\section{As campanhas eleitorais do plebiscito no Pará em 2011 e o jogo político de construção de imagens}

[The plebiscite campaign in Para in 2011 and the political game of image building]

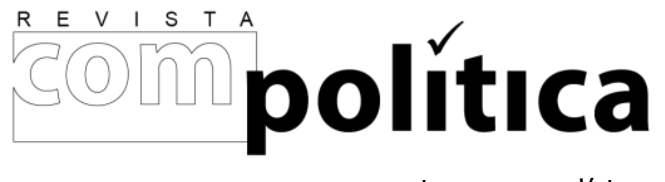

revista compolítica 2017, vol. 7(1)

compolitica.org/revista

ISSN: $2236-4781$

DOI: 10.21878/compolitica.2017.7.1.226

(2) Open Access Journal

\author{
Evelyn Aquino \\ Universidade Federal do Pará \\ [Federal University of Pará]
}

\begin{abstract}
Resumo
O artigo enfoca os modelos de organização e produção de campanhas e políticas no Brasil, com destaque para o papel da televisão e, mais especificamente, do horário gratuito de propaganda eleitoral. $A$ análise se estende a um objeto inédito na história político-democrática do país: a campanha do plebiscito no Pará, em 2011, sobre a criação ou não dos estados do Carajás e do Tapajós, sua composição e suas estratégias de produção. O método analítico utilizou o conceito de política de imagem de Wilson Gomes (2004). Identificou-se uma homogeneização das campanhas que tratavam de diferentes regiões, 0 direcionamento das estratégias à população da capital do Pará, Belém, e o "jogo" político de construção e desconstrução de imagens dos sujeitos que estiveram à frente das campanhas do plebiscito.
\end{abstract}

Palavras-chave: plebiscito no Pará; campanhas eleitorais; política de imagem.

\begin{abstract}
The article focuses on organizational models and production of political campaigns in Brazil emphasizing the role of television and, more specifically, the free time for political propaganda. $A$ unique object in the political and democratic history of the country is analyzed: composition and production strategies of the campaign for a plebiscite in Pará, in 2011, about creating or not the states of Carajás and Tapajós. The analytical method used the concept of image policy of Wilson Gomes (2004). One could identify a homogenization of campaigns that dealt with different regions, the establishment of strategies targeting the population from the capital city of Pará, Belém, and the political "game" of image construction and deconstruction of political actors that conducted the campaign.
\end{abstract}

Keywords: plebiscite in Pará; political campaigns; image policy. 


\section{As campanhas eleitorais do plebiscito no Pará em 2011 e o jogo político de construção de imagens}

Evelyn AQUINO

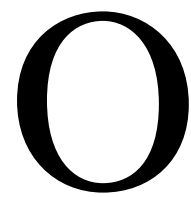
s meios de comunicação tiveram participação fundamental para a consolidação político-democrática no Brasil e transformaram os processos de construção de campanhas eleitorais. A televisão pode ser destacada como protagonista desse fenômeno devido ao jornalismo e à propaganda, ou mesmo, de forma mais específica, ao dispositivo legal do Horário Gratuito de Propaganda Eleitoral $(\mathrm{HGPE})^{1}$, que assegura visibilidade pública à política, garantindo a presença e a comunicação de seus agentes de forma direta com a população (Gomes, 2004)

A questão a ser investigada no trabalho é como se constituíram as campanhas eleitorais do plebiscito no Pará, em 2011, para a criação ou não dos estados do Carajás e do Tapajós, tendo como foco os processos de comunicação. A escolha por essas campanhas se dá pelo pioneirismo de seu acontecimento: o primeiro plebiscito realizado para a decisão popular sobre a delimitação político-administrativa de um Estado, no Brasil. Devido a esse ineditismo, ele engendrou certa confusão entre a imagem de lideranças políticas envolvidas na defesa das propostas e os projetos de criação dos estados em si, objeto de votação da população.

O artigo foi construído em três partes. Inicia-se com a apresentação da metodologia de pesquisa, cujo método de análise utilizado foi o conceito de política de imagem de Wilson Gomes (2004), para organizar a retórica das campanhas em dois sentidos: a) construir a imagem do plebiscito, até então estranho ao entendimento dos cidadãos, para apresentar os projetos para a população decidir como votar; b) observar os espaços de exibição, também estabelecidos pelas campanhas do plebiscito, para agentes públicos construírem imagens desejadas e buscarem resultados positivos para seus interesses políticos.

\footnotetext{
${ }^{1}$ Os autores pesquisados utilizam diferentes terminologias. De acordo com a percepção de que a maioria estudada usa a sigla HGPE, inclusive em trabalhos mais atuais, optou-se por utilizá-la no artigo.
} 
$\mathrm{Na}$ segunda parte, limitou-se a apresentar algumas formas e modelos de organização e produção de campanhas eleitorais e políticas no Brasil, com destaque para a participação da televisão e do HGPE no processo de comunicação política.

E, por fim, analisaram-se as campanhas do plebiscito de 2011, que levou 4.848.495 de eleitores à votação, dos quais $66,6 \%$ decidiram pela não criação do estado de Carajás e $66,08 \%$ votaram contra a criação do estado de Tapajós, a partir de territórios desmembrados do Pará (Tribunal Superior Eleitoral, s.d.). A pesquisa explicita a estruturação legal, mas recai, especialmente, sobre as estratégias de produção dos programas do HGPE.

\section{Metodologia}

O HGPE no rádio e na TV foi exibido do dia 11 de novembro até o dia 7 de dezembro de 2011. Os programas tiveram 10 minutos de duração, cada. O horário no rádio foi das $7 \mathrm{~h}$ às $7 \mathrm{~h} 10$ e das $12 \mathrm{~h}$ às $12 \mathrm{~h} 10$, já na televisão aconteceu das $12 \mathrm{~h}$ às $12 \mathrm{~h} 10$ e das $19 \mathrm{~h} 30$ às 19h40, de acordo com o horário de Brasília. Os programas foram transmitidos às segundas, terças, quartas, sextas e sábados, ${ }^{2}$ sendo que em um dia eram reservados às frentes pró e contra o estado do Tapajós e, no dia seguinte, pró e contra o estado do Carajás.

O HGPE do plebiscito propiciou espaços de tempo proporcionalmente igualitários às frentes de campanha, a despeito da diferença de tempo que considera a representação dos partidos no Congresso Nacional em campanhas a cargos eletivos. A qualidade de produção dos programas também foi nivelada, diferentemente da estrutura econômica das diferentes siglas que lançam candidaturas às eleições. No entanto, os aspectos legais democráticos não garantiram, por sua vez, a exposição racional do conteúdo dos projetos, mas a predominância do espetáculo passional, imediatista e tendencioso de interesses políticos e econômicos. Sobre a polaridade entre conteúdo racional e emocional, Panke e Cervi (2011) explicam:

\footnotetext{
${ }^{2}$ Não houve exibição de programas às quintas-feiras e domingos.
} 
Toda análise de conteúdo de HGPE precisa levar isso em consideração e se propor a analisar tanto os elementos que propiciam um debate político racional, quanto aqueles que estimulam a emotividade e empatia não-racional. Nesse sentido, a televisão como difusora de conteúdos eleitorais produz uma gramática do sentimento. $\mathrm{O}$ uso de recursos como áudio, edição, mudança de luz e câmera, vozes e outros reconfiguram a realidade e induzem sentimentos que são capazes de afetar a avaliação dos eleitores (Panke; Cervi, 2011, p. 5).

Dos 80 programas veiculados no HGPE, foram identificados 33 programas totalmente repetidos - 18 do Não e 15 do Sim. Além dos programas totalmente repetidos, outros misturaram partes já apresentadas em programas anteriores com conteúdos novos, o que não deixou de ser a composição de um novo programa, estrategicamente orientado para se configurar dessa forma.

Sortearam-se aleatoriamente os programas a serem analisados, para garantir que todos tivessem a mesma chance de serem escolhidos; os repetidos foram incluídos no sorteio, pois essa conformação é, em si, uma estratégia enunciativa. Dessa seleção de 80 programas, optamos por estudar 10 dias de veiculação, com um do Sim e um do Não por dia, fechando um total de 20 programas para análise, quantidade razoável que nos possibilitou obter uma informação expressiva desse estrato.

Apesar de algumas iniciativas de explicação da consulta plebiscitária ao longo dos programas, a apresentação das ideias muitas vezes se confundiu com a imagem de políticos, seja pelo caráter experimental - o primeiro plebiscito realizado para a escolha do futuro de um estado -, seja pelos interesses pessoais dos atores públicos envolvidos nas campanhas, cujas estratégias discursivas eram tanto de denúncia dos interesses do oponente, quanto de silenciamento de objetivos particulares.

Para Gomes (2004, p. 201), a diferença entre a apresentação pública de um debate de interesse comum e a propaganda está no fato de a primeira ser "dialógica", enquanto que a segunda é "didática", isto é, a exposição pública é uma interlocução já em processo ou que se inicia, já a propaganda ensina e persuade. A interlocução deve contribuir com o aprendizado, no entanto, ambas devem ter um caráter informativo e competência argumentativa (Gomes, 2004, p. 201). 
O HGPE propiciou visibilidade para o plebiscito, para que o público conhecesse as propostas e os atores sociais que deveriam fazer parte delas. Entendem-se esses dois eixos como: a) os projetos que seriam votados e b) os atores em evidência - cujos objetivos foram além de explicar as propostas, mas obter exposição de imagem -, sobre o que recai nossa análise quanto à concepção de Gomes (2004, p. 242) sobre "política de imagem", que indica "a prática política naquilo que nela está voltado para a competição pela produção e controle de imagens públicas de personagens e instituições políticas". A "imagem pública" corresponde a "um complexo de informações, noções, conceitos, partilhado por uma coletividade qualquer e que o caracteriza. Imagens públicas são concepções caracterizadoras". (Gomes, 2004, p. 254).

Os indivíduos envolvidos na criação das campanhas televisivas de 2011 estabeleceram uma relação de forças na construção da imagem pública dos sujeitos participantes do jogo político, disputando a todo momento a construção e a desconstrução de suas imagens, tendo, nas eleições, o momento oportuno para otimizar essa disputa.

As atividades institucionais da política incluem as disputas entre as forças nela presentes. É o jogo político formado pelas negociações, por um extenso repertório de interações e comportamentos para a composição dessas forças que se dão nas concorrências da arena política (Gomes, 2004). Esse jogo pode ser percebido facilmente ou está implícito no conteúdo da propaganda, mais difícil de apreender, o que exige um esforço para que ele possa ser desvelado.

\section{A trajetória das campanhas eleitorais no Brasil}

O fim da ditadura, após mais de vinte anos de controle do regime militar sobre vários âmbitos sociais, dentre eles, a imprensa e a propaganda de Estado, possibilitou o processo de restauração democrática no país. O campo político e a sociedade se viram diante de novas oportunidades de publicidade política ancorada por meios eletrônicos e democráticos. Nesse âmbito, surgiram os partidos políticos e as vozes representativas se multiplicaram (Gomes, 2004). 
O HGPE em rádio e televisão surgiu em 1962, como uma concessão pública de espaço dentro da programação das empresas de rádio e televisão para a comunicação midiática da política com a sociedade. É controlado pela justiça eleitoral e pago pelo Estado por meio de renúncia fiscal (Gomes, 2004). Segundo Maria Helena Weber (1994),

[...] a política aparece como usurpadora de tempo e espaço, como um delito cometido pelo seu discurso diferenciado e realista como poder de contrariar e interromper a programação. Nesta medida, compete diretamente com o discurso televisivo, pois ambos exercitam seu poder junto ao receptor (Weber, 1994, p. 82).

À vista disso, as empresas privadas se veem obrigadas a ceder espaço em suas emissoras de rádio e televisão para candidatos e partidos que não necessariamente defendem os mesmos interesses das empresas midiáticas. Há ainda a dificuldade econômica. A propaganda política se torna muito sofisticada devido aos altos custos de sua produção e veiculação para o acesso dos interessados de forma equânime (Gomes, 2004).

O objetivo de elaboração de estratégias comunicativas que constituem a propaganda do HGPE é ter o potencial de gerenciar os assuntos da agenda pública de forma a garantir uma disputa direcionada à interpretação da realidade. As temáticas de interesse público podem ser reinseridas para discussão dependendo da competência comunicativa do HGPE, conforme explica Rubim (2000):

Uma interação, desigual mas combinada, entre a agenda da sociedade detectada através de sondagens de opinião e expressa em atos e falas de atores sociais - a agenda da mídia e a agenda elaborada pelo horário eleitoral conformam, pela via da complementação e do confronto, uma agenda pública de temas inscrita no cenário eleitoral (Rubim, 2000, p. 48).

Weber (1994) o classifica como "Espetáculo Político Arbitrário", pois este permanece por um determinado período na programação, de modo esteticamente unificado nas concorrentes empresas de comunicação e independentemente das características da audiência de cada veículo. Enquanto espetáculo, ele possui uma natureza "estética 
híbrida, que apresenta a política misturada a linguagens e gêneros" (Weber, 1994, p. 91). Trata-se da apresentação do HGPE com formatos de telejornal, humorístico, de telenovela, programa de entrevistas em estúdio ou entrevistas em locais públicos quando da abordagem de transeuntes para responderem a perguntas determinadas.

A consulta plebiscitária de 2011 foi se materializando ao longo de uma história de disputas entre diversos interesses, em que várias estratégias discursivas foram se construindo até a consolidação do momento em que a população foi às urnas decidir. Anteriormente, outros estados e territórios foram criados pelo governo na região Norte, sem consulta pública, entre eles, o Acre, em 1956; Rondônia e Mato Grosso do Sul, em 1981; Amapá e Roraima, em 1984; e Tocantins, em 1988.

Houve também a realização de outros plebiscitos e referendos ${ }^{3}$ no país. O referendo de 6 de janeiro de 1963 propôs a escolha sobre o futuro político do Brasil, se deveríamos continuar em um regime Parlamentarista ou não. A população decidiu contra esse sistema, votando pelo Presidencialismo (Tribunal Superior Eleitoral, s.d.).

Em 21 de abril de 1993, os brasileiros foram convocados a decidir via plebiscito sobre qual sistema de governo entraria em vigor no país - Monarquia ou República e Parlamentarismo ou Presidencialismo. República e Presidencialismo foram as escolhas (Tribunal Superior Eleitoral, s.d.). O último referendo ${ }^{4}$ realizado, em 23 de outubro de 2005, versava sobre "a proibição do comércio de armas de fogo e munições no país", a partir da Lei 10.826/2003, que modificava o Artigo 35 do Estatuto do Desarmamento, proibindo "a comercialização de arma de fogo e munição em todo o território nacional, salvo para as entidades previstas no art. $6^{\circ}$ do estatuto" (Tribunal Superior Eleitoral, s.d.). A mudança traria consequências significativas tanto para a indústria de armas quanto para a sociedade. O povo foi às urnas e votou contra a comercialização de armas de fogo (Tribunal Superior Eleitoral, s.d.).

\footnotetext{
${ }^{3}$ No site do TSE, ambos, plebiscito e referendo, estão definidos como "consulta ao povo para decidir sobre matéria de relevância para a nação em questões de natureza constitucional, legislativa ou administrativa". A diferença entre eles, em relação à "criação do ato legislativo ou administrativo que trate do assunto em pauta", é que o plebiscito é convocado anteriormente à criação, enquanto que o referendo é realizado após, apresentando à população as opções de confirmar ou recusar a proposta (Tribunal Superior Eleitoral, s.d.).

4 Sobre o referendo das armas no Brasil, ver Veiga e Santos (2008). O artigo aborda as estratégias de comunicação e os efeitos persuasivos sobre o eleitor das campanhas da Frente Parlamentar por um Brasil sem Armas (SIM) e da Frente Parlamentar pelo Direito da Legítima Defesa (NÃO).
} 
O HGPE ganhou relevância como objeto de pesquisa acadêmica a partir da década de 1980, graças à expansão do rádio e da TV como meios de comunicação massiva de candidatos em campanhas eleitorais. O papel informativo, os modelos de atuação e as estratégias de comunicação em campanhas suscitaram o interesse de estudo da linguagem do HGPE. O principal método de pesquisa empregado era a Análise de Conteúdo de influência internacional, enquanto que os principais interesses de estudo estavam na "retórica, argumentação, fonte e conteúdo de cada segmento de HGPE para disputas majoritárias - candidatos a prefeito, governador, senador e presidente" (Panke; Cervi, 2011, p. 395).

Além destas importantes funções que dão visibilidade a políticos e partidos, segundo Panke e Cervi (2011, p. 392) o HGPE "indica aos eleitores o início do 'tempo da política', o momento em que a política entra nos espaços privados das famílias, através da televisão e do rádio, invertendo a lógica do debate político" que passa a ser conduzido do espaço privado para a discussão pública.

Alguns momentos da propaganda política televisiva merecem ser contextualizados pelo seu papel comunicativo. Dentre eles, a campanha das Diretas Já (1983-1984), momento de intensas reivindicações populares exigindo a convocação de eleições diretas para o cargo de Presidente da República. Segundo Lattman-Weltman (2003, p. 142), o "maior movimento de mobilização política de massas da história republicana até então" representou o marco de decisão sobre o tratamento que seria dado à política pela mídia, em relação ao público, de forma geral.

O período das Diretas Já foi marcado por grande efervescência entre os produtos e meios de comunicação. As novelas, a agenda do jornalismo e da televisão exibiram o momento vivido pelo Brasil, abrindo espaço para entrevistas e discussões sobre política (Lima, 1995). A partir das eleições municipais de 1985 ,

[...] assistimos a um notável desenvolvimento do marketing político e a um aperfeiçoamento constante da qualidade dos HGPE, tanto no que diz respeito ao desempenho dos candidatos ao falar em público na tevê, quanto no que concerne à configuração geral dos programas, incluindo aí os meios técnicos, como a nitidez da imagem e a clareza do som, as combinações semióticas e a multiplicidade de gêneros discursivos. É praticamente consensual entre os 
especialistas em comunicação política que as eleições presidenciais de 2002 representam o apogeu dessa evolução (Piovezani, 2009, p. 261).

Na primeira eleição direta para presidente da República em 1989 (Lei 7.773), o HGPE experimentou diversos ajustes e refinamentos, dentre eles, "a tentativa de mimetismo entre a programação normal da tevê e os programas televisivos dos candidatos no HGPE, por meio da simulação de telejornais, talk-shows e até mesmo de telenovela" (Piovezani, 2009, p. 252), além de paródias com o discurso publicitário, comparando o consumo de produtos e marcas ao de sujeitos. Na década de 1980, o investimento na "psicologização" do eleitorado e do discurso político ampliava as características da personalidade individual e coletiva das pessoas, com o intuito de demarcar um comportamento político nelas.

Conforme Panke e Cervi (2011, p. 394), a campanha presidencial de 1989 é considerada um marco de um novo modelo do HGPE para a pesquisa sobre Comunicação em campanhas eleitorais. A propaganda eleitoral passa a ter estratégia organizada: "tratar de temas da atualidade usando uma argumentação ficcional".

Para Figueiredo et al. (1997, p. 184), três características ganharam relevância, neste período, para os pesquisadores de Comunicação e Ciência Política: "o desempenho performático do candidato vitorioso, a interveniência dos programas eleitorais na formação das intenções de voto e a interferência da mídia no processo eleitoral", as análises se centraram nos ambientes políticos midiáticos e no discurso televisivo dos participantes.

Em 1994, as eleições foram "casadas". Além da escolha do presidente da República, escolheram-se, concomitantemente, deputados estaduais e federais, senadores e governadores. O HGPE esteve amparado pela Lei 8.713, de 30 de setembro de 1993, que proibia a exposição de trucagens, imagens externas e colaboração de convidados. A explicação para isso pautava-se em duas questões: inibir a exorbitante atuação da mídia, como a ocorrida nas últimas eleições, destacando a política e não as técnicas empregadas e garantir um processo igualitário para os candidatos, por meio da redução dos custos das campanhas (Piovezani, 2009). 
Segundo Albuquerque (2004, p. 468), a justificativa de otimizar a discussão política foi um pretexto para "marginalizar o HGPE como fórum do debate político e, por tabela, favorecer a eleição de Fernando Henrique Cardoso (PSDB) à Presidência da República". Restrição cujo objetivo era coibir a mobilização feita pelo candidato Luiz Inácio Lula da Silva que começou a percorrer o Brasil com as Caravanas da Cidadania mostrando a realidade de um Brasil excluído da mídia hegemônica (Almeida, 2002).

No que tange aos processos de comunicação sistematizados no HGPE televisivo do plebiscito de 2011, compreende-se que o diálogo direto foi uma das principais estratégias elaboradas pelas frentes de campanha para construção e desconstrução de imagens, expondo contradições entre os sujeitos políticos envolvidos, provocações que demandavam respostas e um debate democrático de demandas sociais importantes.

Segundo Dias (2014), observar a interlocução de opiniões e propostas de interesse público direciona a escolha do eleitor e otimiza a competência informacional de uma campanha. A autora explica que o diálogo direto acontece "quando candidatos mencionam diretamente o oponente a fim de marcar suas diferenças de posição a respeito de determinado tema", diferentemente do diálogo indireto, que se dá quando "candidatos assumem posições ou fazem afirmações sobre um mesmo tema, sem mencionar o oponente diretamente, mas permitindo ao eleitor comparar propostas e tomar decisões informadas" (Dias, 2014, p. 6).

O diálogo, para Figueiredo et al. (1997), também é fundamental entre candidatos e eleitores que buscam a complementaridade de seus interesses, enquanto estes querem a realização de suas demandas sociais, aqueles buscam conquistar cargos públicos.

A interlocução entre as frentes de campanha e os eleitores foi menos buscada nos programas. O objetivo inicial visava o diálogo com a população da capital do Estado, Belém, região onde ficaria o Pará remanescente. Esse direcionamento se revelou em uma estratégia ancorada nas três pesquisas de opinião realizadas sobre o plebiscito nos dias 11 e 25 de novembro e 9 de dezembro de 2011. As sondagens indicaram que o "Não" apresentava larga vantagem à frente do "Sim", sendo que 2/3 dos eleitores do Estado 
estão localizados em Belém e, desse número, mais de $90 \%$ declararam ser contra a criação dos estados.

\section{As campanhas comunicacionais do plebiscito no Pará em 2011}

O plebiscito realizado no Pará foi uma votação popular, cuja decisão do cidadão não foi em relação a candidatos e partidos políticos, mas em relação às propostas de reorganização do mapa do atual estado para ser dividido em três. $\mathrm{O}$ atual Pará conta com 1.248.000 km² de extensão e, caso a divisão do Estado viesse a ser aprovada, ficaria com uma área menor, correspondente a $20 \%$ desse total. O restante do seu território formaria dois novos estados, o do Carajás, que levaria $23 \%$ da área atual e o do Tapajós, com $57 \%$ desse quantitativo. No dia do pleito, o eleitor respondeu às seguintes perguntas: "Você é a favor da divisão do estado do Pará para a criação do estado do Carajás?" e "Você é a favor da divisão do estado do Pará para a criação do estado do Tapajós?” (Tribunal Superior Eleitoral, s.d.).

O planejamento, a organização e a execução das campanhas do plebiscito de 2011 foram regulamentados pelo Tribunal Superior Eleitoral, por meio da Resolução no 23.354/2011, que dispôs sobre a propaganda eleitoral gratuita e obrigatória do plebiscito.

O TSE autorizou o registro das frentes favoráveis e contrárias ao surgimento dos novos estados, compostas por políticos da Assembleia Legislativa, do Senado e da Câmara dos Deputados, que tiveram a incumbência de organizar e promover as campanhas do plebiscito (Senado Federal, s.d.). 
Quadro 1 - Frentes ${ }^{5}$ registradas no Tribunal Regional Eleitoral do Pará

\begin{tabular}{l|l|l}
\hline & TAPAJÓS & CARAJÁS \\
\hline $\begin{array}{l}\text { Frentes contra a } \\
\text { criação do } \\
\text { estado }\end{array}$ & $\begin{array}{l}\text { Deputado Estadual Celso } \\
\text { Sabino de Oliveira (PR-PA) }\end{array}$ & $\begin{array}{l}\text { Deputado Federal Zenaldo } \\
\text { Rodrigues Coutinho Júnior (PSDB- } \\
\text { PA) }\end{array}$ \\
\hline $\begin{array}{l}\text { Frentes pró- } \\
\text { criação do } \\
\text { estado }\end{array}$ & $\begin{array}{l}\text { Deputado Federal Joaquim de } \\
\text { Lira Maia (DEM-PA) }\end{array}$ & $\begin{array}{l}\text { Deputado Estadual João Salame } \\
\text { Neto (PPS-PA) }\end{array}$ \\
\hline
\end{tabular}

Fonte: Tribunal Superior Eleitoral, s.d.

A propaganda das frentes favoráveis e contrárias à formação dos estados foi liberada pelo TSE a partir do dia 13 de setembro de 2011. Houve propaganda na internet, realização de comícios, shows, debates, distribuição de panfletos e cartazes, circulação de carros de som, pesquisas de opinião com a obrigatoriedade de registro no TRE-PA. A exposição de outdoor foi proibida.

Observou-se de forma assistemática a repercussão midiática sobre o assunto para expandir e compreender a contextualização dos debates no HGPE, sendo este último o recorte de análise delimitado. A cobertura do plebiscito se deu em diversos telejornais com divulgação de informações sobre a votação, entrevistas com os responsáveis pelas frentes pró e contra a criação dos estados, com a população das diferentes regiões, com artistas regionais e com agentes do âmbito jurídico e político, reportagens nas escolas com crianças e jovens, denúncias de campanha irregular, distribuição e segurança das urnas no Estado, divulgação de pesquisas de opinião. Foram feitas inserções da propaganda política na rede televisiva aberta.

A agenda midiática sobre o plebiscito ocorreu em várias emissoras com diferentes intensidades, alguns programas e jornais que retomaram o tema com frequência foram: Jornal da Noite (TV Cultura); Jornal RBA, Metendo Bronca, Açaí Vip, Argumento, Barra

\footnotetext{
${ }^{5}$ Colocamos aqui os nomes publicados na página do TRE em que consta "Frentes Plebiscitárias", mas no link "Prestação de Contas das Frentes Plebiscitárias" encontramos as seguintes denominações: Frente em defesa do Pará contra a criação de Carajás, Frente contra a criação do estado do Tapajós, Frente por um Pará mais forte e Frente pró estado do Tapajós.
} 

SBT); Balanço Geral, Pará Record (TV Record); Nazaré Notícias (TV Nazaré).

Em âmbito nacional, além das reportagens jornalísticas em jornais diários e entrevistas, vale destacar o quadro JN no ar, do Jornal Nacional da TV Globo, que fez uma série de três reportagens sobre o plebiscito em Belém, Marabá e Santarém, ${ }^{6}$ com entrevistas a moradores locais, esclarecimentos sobre as propostas, com mediação da jornalista Cristina Serra. ${ }^{7}$

Apesar do conteúdo mostrado, a cobertura da mídia sobre o plebiscito ficou aquém das necessidades de esclarecimento da população, os movimentos dos bastidores foram omitidos por uma cobertura feita à distância, intensificada apenas às vésperas da realização do plebiscito. Diferentemente da importância e da atenção dada ao Pará por veículos de comunicação estrangeiros como o Wall Street Journal e a Revista Newsweek, que, com meses de antecedência, já tinham profissionais acompanhando in loco a movimentação do pleito.

Adentrando a análise das campanhas televisivas no HGPE, o primeiro aspecto observado em relação à demarcação de discursos antagônicos foi a impossibilidade de diferenciar um programa organizado pelas frentes direcionadas ao projeto do Carajás ou ao do Tapajós. Além disso, programas de uma frente pró ou contra determinado estado foram repetidos pela do outro e vice versa, o que indica que não houve a presença de uma linguagem própria das frentes para cada proposta de estado, não se exibiram as particularidades históricas, culturais e econômicas das regiões separadamente. ${ }^{8}$ Essa homogeneização das campanhas em relação aos novos estados pode ter sido uma constatação dos grupos que produziram as campanhas e que foi assimilada e levada para

\footnotetext{
${ }^{6}$ As duas últimas foram as possíveis capitais dos estados do Carajás e do Tapajós, respectivamente.

7 Jornalista paraense, especialista em política, trabalha como repórter e apresentadora no Jornal do Brasil, O Globo, Tribuna da Imprensa e TV Globo.

${ }^{8}$ Tapajós vem experimentando a mineração, principalmente de bauxita, o cultivo da soja e da madeira. Carajás tem como forte atividade econômica, a mineração, a pecuária e a madeira. A grande massa de imigrantes que o Pará recebeu no passado e de certa forma ainda recebe, diversificou amplamente sua identidade, despojando-a cada vez mais de sua cultura mais tradicional que é de influência indígena. A região do Carajás é indiferente a essa raiz indígena da população paraense, sendo mais próxima da cultura do Centro-Oeste e Nordeste do país. A cultura do Carajás é mais afinada com o transporte rodoviário do que o fluvial, com a geografia das pastagens e fazendas, a mata em pé (Pinto, 2013).
} 
as urnas pelo povo, o que fez com que o resultado dos dois estados fosse parelho e a discussão das necessidades e particularidades de cada região, apagada.

A metodologia das Pesquisas Vox Populi ${ }^{9}$ também dificultou a distinção entre os dois estados, ao propor uma pergunta vaga aos entrevistados: "Em caso de plebiscito, o eleitor é a favor ou contra a divisão do Pará em três estados?". Contudo, no dia da votação as opções de voto se deram em relação ao Tapajós e ao Carajás, separadamente. Esse detalhe pode ter prejudicado o Tapajós, que contava com a simpatia da região do Pará remanescente.

Segundo Lúcio Flávio Pinto (2011), a omissão do Tapajós no método de coleta da opinião pública nas pesquisas pode ter prejudicado a decisão favorável à criação do Estado. Isso porque muitas famílias oriundas do Pará remanescente vivem nessa região. Além disso, a luta do Tapajós parece mais justa à população que ficaria no Pará por ser mais antiga e fundamentada nos limites geográficos de Santarém, anteriormente eleita a terceira maior cidade da Amazônia. A maioria da população do Tapajós é de origem paraense e de imigrantes que estão há muito tempo na região. Em contrapartida, em Carajás, a predominância é de pessoas provenientes de outros estados - como explicitado anteriormente - principalmente do Maranhão, Estado que possui uma rivalidade econômica com o Pará, por ser visto como usurpador dos bens naturais deste. Daí a iniciativa dos emancipacionistas do Carajás de recorrer à justiça para que o plebiscito não fosse realizado em todo o Pará (Pinto, 2011).

A análise mostrou que as frentes de campanha trabalharam com estratégias argumentativas que ofertaram diferentes discursos. As frentes contrárias aos novos estados investiram nos discursos a) da integridade e união da população contra a divisão, por meio de apelos à cultura; b) da ingerência externa de grupos políticos e econômicos que estariam manipulando a decisão da população para alcançar benefícios particulares; c) da condenação dos novos estados à inviabilidade administrativo-financeira. Por outro lado, as frentes favoráveis aos novos estados trabalharam com os discursos a) do

\footnotetext{
${ }^{9}$ A Vox Populi é uma empresa que realiza pesquisas de opinião e de mercado, fundada em 1984. A instituição integra a Associação Brasileira de Empresas de Pesquisa (ABEP), a Esomar e a Associação Mundial de Pesquisa de Opinião Pública (WAPOR). Seu corpo profissional é formado por sociólogos, cientistas políticos, economistas, estatísticos, administradores, psicólogos, profissionais do marketing e da comunicação (Vox Populi, s.d.).
} 
desenvolvimento econômico, única solução para todos os problemas do Pará; b) dos estados, criados anteriormente, que deram certo; c) da extensão territorial como sinônimo de ingovernabilidade; e d) do abandono pela gestão.

As possibilidades de recursos técnicos empregados nas campanhas para construir os argumentos sobre o plebiscito foram diversificadas nas campanhas: videoclipes, entrevistas com especialistas econômicos e artistas, apresentadores e jornalistas em estúdio e em gravações externas, histórias de vida, carreatas das campanhas, entrevistas com pessoas nas ruas, debates entre os líderes das frentes. As campanhas no meio televisivo foram dispostas aos telespectadores com essa pluralidade de formatos multilinguísticos, em processo fluido de interação entre eles.

Desde o primeiro programa das campanhas do plebiscito $^{10}$, a propaganda apresentou um caráter didático para explicá-lo como um acontecimento político inédito na história do Brasil e desafiador tanto para as lideranças políticas das frentes, quanto para os produtores, especialistas na criação de campanhas eleitorais de candidatos. Isso tudo para que a população conhecesse o pleito e se inteirasse sobre como proceder no dia da votação.

Uma apresentadora entrou em estúdio para explicar: "Dia 11 de dezembro é dia de voto. Não é um voto pra eleger este ou aquele candidato. Você vai decidir sobre a divisão ou não do Pará". A apresentadora é conhecida, trabalhou nas Organizações Romulo Maiorana $^{11}$. A câmera registra a cena em plano aberto, mostrando a jornalista de corpo inteiro como nos estúdios dos telejornais, com o mapa do Pará ao fundo. O conteúdo dele é cheio de florestas. O tom e a postura da profissional são de quem explica algo importante aos telespectadores.

As principais estratégias comunicacionais abordadas pelas frentes contrárias aos estados destacaram o discurso de manutenção da união do Pará, da grandeza territorial, da riqueza de recursos, do multiculturalismo e do dinamismo das atividades econômicas ameaçados pela divisão.

\footnotetext{
${ }^{10}$ Exibido no dia 11/11/2011, à tarde, da Frente contra Carajás.

${ }^{11}$ As Organizações Romulo Maiorana são detentoras de emissoras de televisão aberta e de rádios AM e FM, TV a cabo e provedor de internet, entre outros empreendimentos empresariais (Donos da mídia, 2013).
} 
O "ser paraense" foi representado pelos contrários à divisão nas imagens de símbolos presentes no imaginário coletivo da região do Pará remanescente, principalmente imagens editadas de Belém, os pontos turísticos, a Bandeira, o Hino, a gastronomia, a presença de artistas locais. As imagens valorizam o orgulho de pertencer ao Estado, orientadas pelo slogan da campanha dos unionistas: "Não e não! Ninguém divide o Pará".

O Não construiu uma imagem positiva da cidade e de seus moradores como defensores dos interesses do atual Pará, não dividido. Trechos do hino estadual foram interpretados na maioria dos programas na voz de cantores paraenses e de pessoas desconhecidas: "Ó Pará, quanto orgulha ser filho, de um colosso tão belo e tão forte. Juncaremos de flores teu brilho; do Brasil, sentinela do Norte. E, a deixar de manter esse brilho, preferimos mil vezes a morte" (Programa da Frente contra Carajás, dia 11 nov. 2011, 12h-12h05).

Figuras 1, 2 e 3 - Cena de clipe musical interpretado por Leila Pinheiro

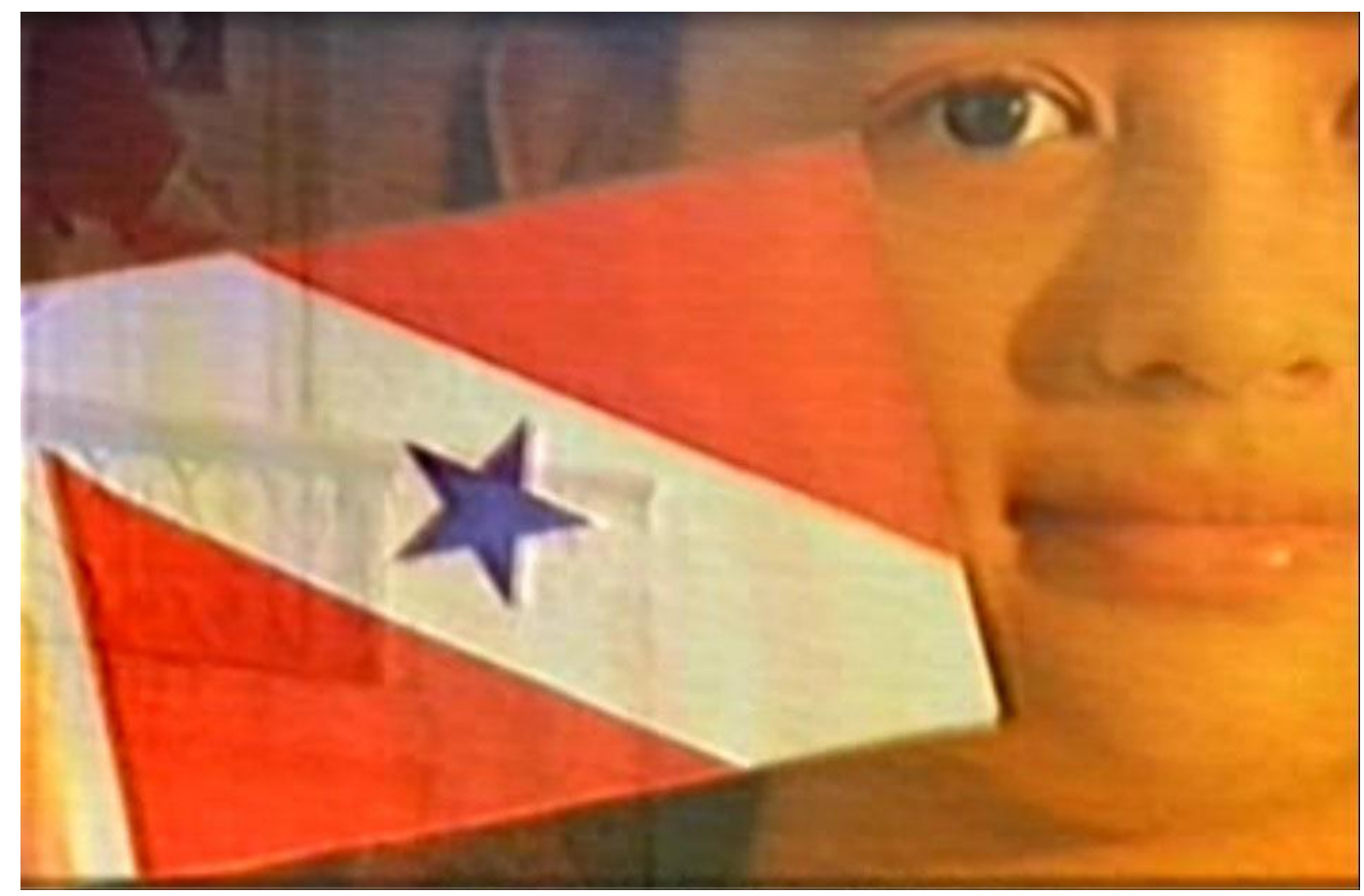



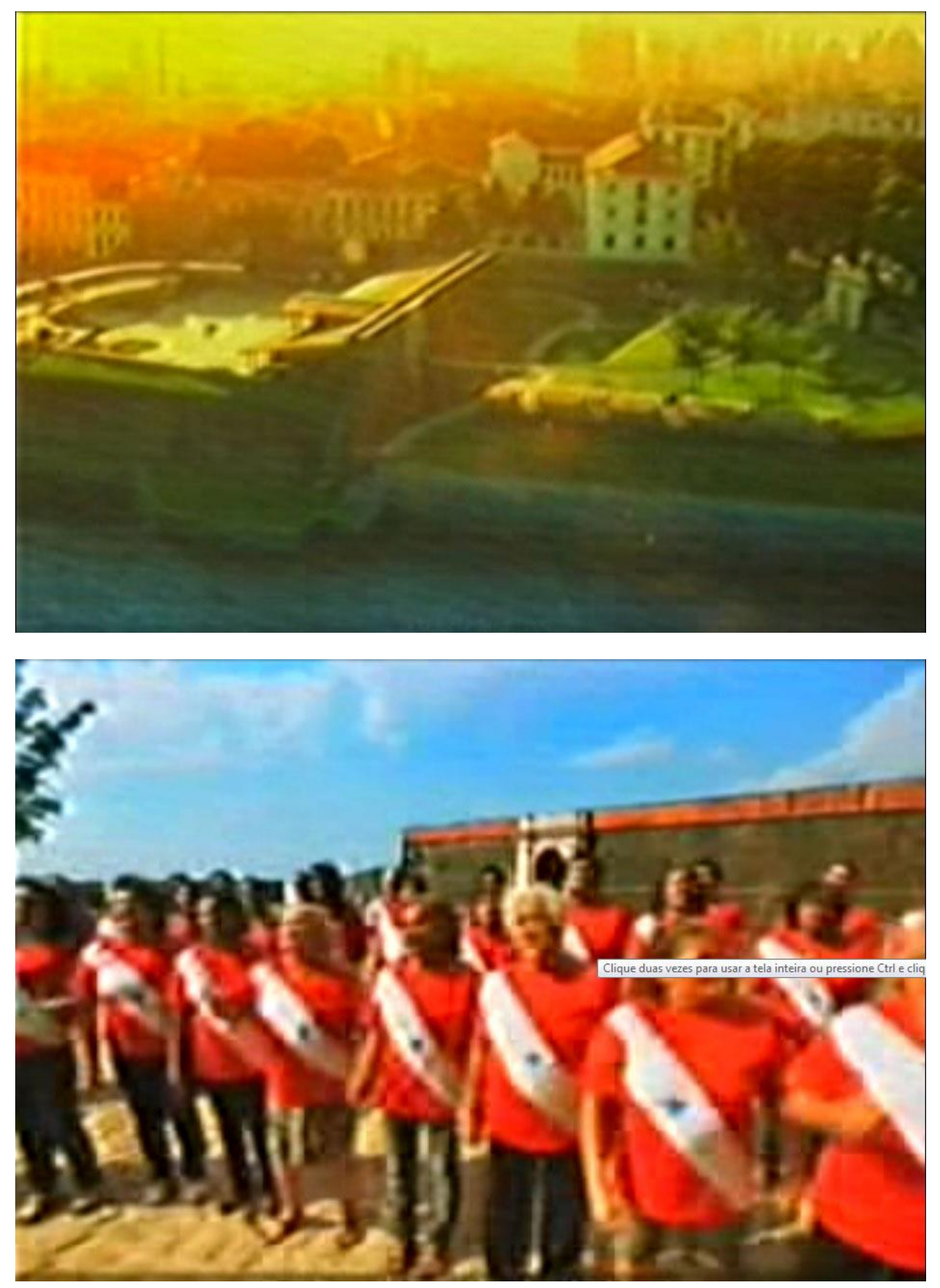

Fonte: Programa da Frente contra Carajás, dia 11 nov. 2011.

O Sim, por sua vez, explorava a miséria como realidade na vida da população das regiões separatistas, onde as pessoas não compartilham das mesmas possibilidades de 
crescimento que os habitantes de Belém. Implicitamente, a estratégia discursiva acionada atacava e acusava os moradores da capital de terem uma vida abastada às custas do trabalho da população das regiões que buscam a emancipação, pois os recursos destas seriam direcionados à capital.

No videoclipe mais exibido nos programas das frentes pela criação dos estados, a linguagem e os jogos de palavras apareceram como estratégias discursivas em uma espécie de súplica à piedade de Belém (Figuras 4, 5 e 6):

Se nada muda, todo mundo perde, o Pará fica parado, tudo fica como está. Se a gente muda, todo santo ajuda. Vamos dividir para multiplicar [...] Belém, não feche os olhos pra esse povo não [...] Se é maior a sua força, se é maior sua população, diga sim pra essa esperança que o futuro desse povo tá na sua mão. Se é bom pra todo mundo não me diga não [...] se é bom pra todo mundo se lembre de mim e me diga sim (Programa da Frente pró Carajás, 11 nov. 2011, 12h05-12h10).

Figuras 4, 5 e 6 - Principal videoclipe da campanha do Sim

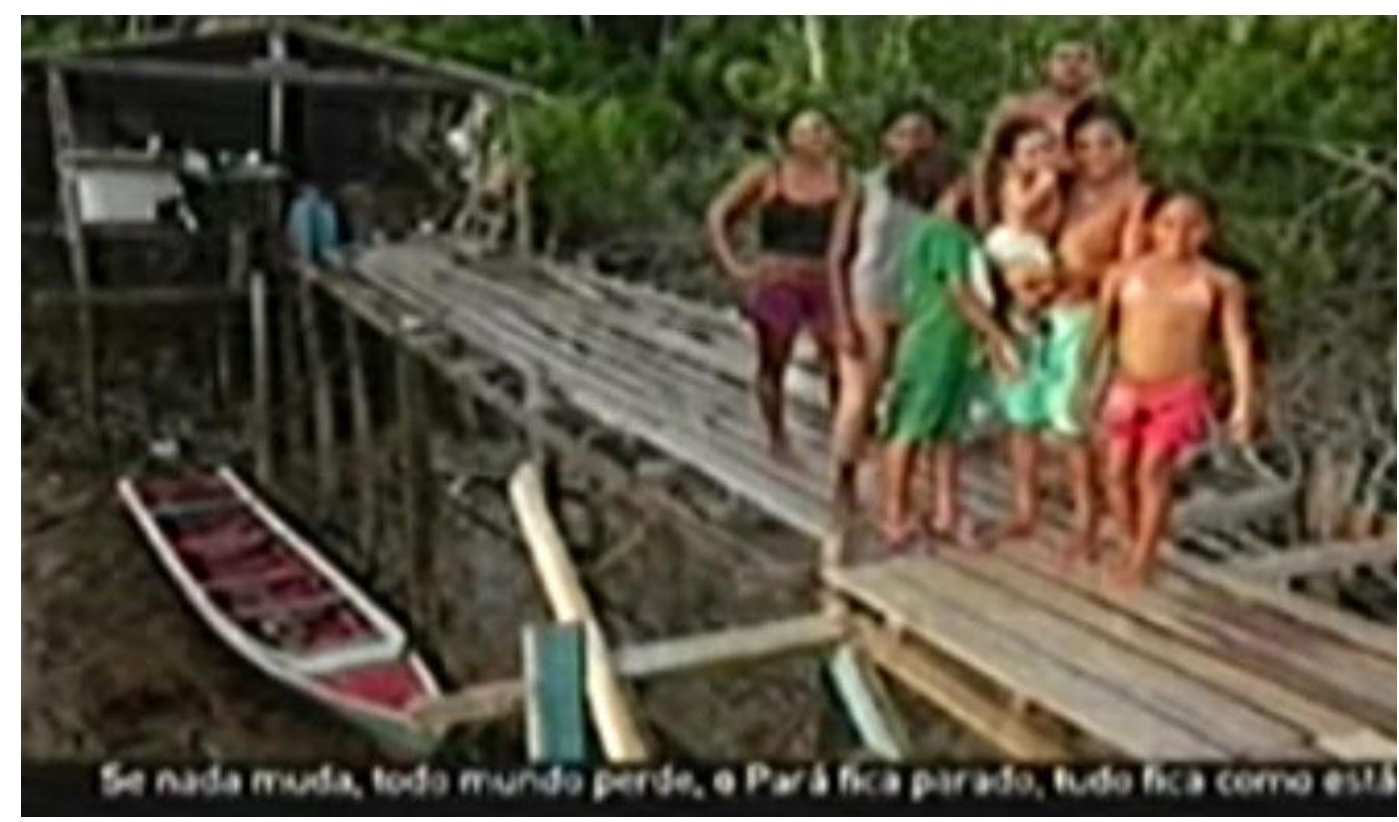



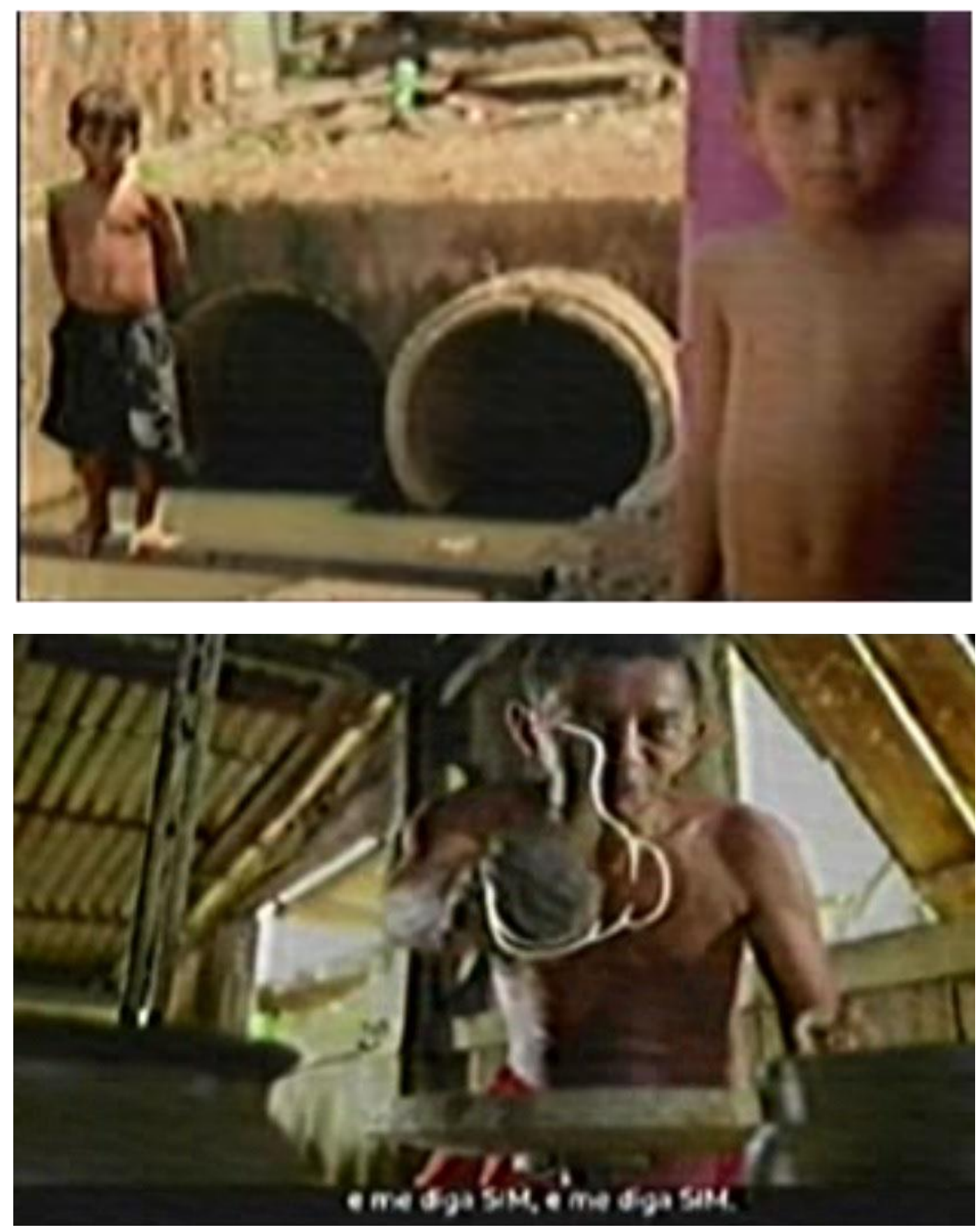

Fonte: Programa da Frente pró Carajás, dia 11 nov. 2011, 12h05-12h10.

A presença física das lideranças das frentes de campanha se deu de forma muito pontual, pois foram vistas apenas de forma bastante discreta, em carreatas. Os deputados João Salame (PPS-PA), líder da frente a favor do Estado do Carajás e Zenaldo Coutinho 
(PSDB-PA), líder da frente contra a criação desse estado se manifestaram nos dias 11 de novembro e 06 de dezembro, respectivamente, nos programas das frentes que presidiram.

Os programas noturnos do dia 02/12/2011, do Sim e do Não, referentes ao Tapajós, tiveram a realização do último debate como temática. O debate foi exibido pela TV RBA Canal 13, no dia $1^{\circ}$ de dezembro de 2011 com os presidentes das frentes de campanhas. $\mathrm{Na}$ apresentação do mediador, jornalista Luciano Júnior, o debate foi transmitido para 87 municípios paraenses pelos canais RBA 13 (analógico) e 36 (digital), além da Rádio Clube do Pará AM e do Portal DOL.

O debate com os presidentes das frentes representou o momento em que os líderes obtiveram maior visibilidade e oportunidade de confronto de ideias. Os participantes buscaram o contato direto, intimista e de afinidade com o público. O estilo de exposição era simples, claro e descontínuo. Inicialmente, a postura dos políticos foi de cordialidade uns com os outros, mas, à medida que as disputas discursivas foram se acentuando, pela posse da palavra, legitimação de seus discursos e descredenciamento do argumento oponente, eles começaram a questionar os interesses políticos dos adversários, bem como as alianças político-partidárias empreendidas, cotejando-as com as contradições dessas mesmas afinidades.

A principal acusação lançada a Salame, por exemplo, foi o fato de o deputado ter apoiado a criação do Carajás, mas ser vice-líder do governo de Simão Jatene, que ele acusava de não solucionar os problemas do Pará. João Salame foi eleito Prefeito de Marabá em 2012, cidade escolhida para ser capital do Estado do Carajás. 
Figuras 7 e 8 - Trechos do debate
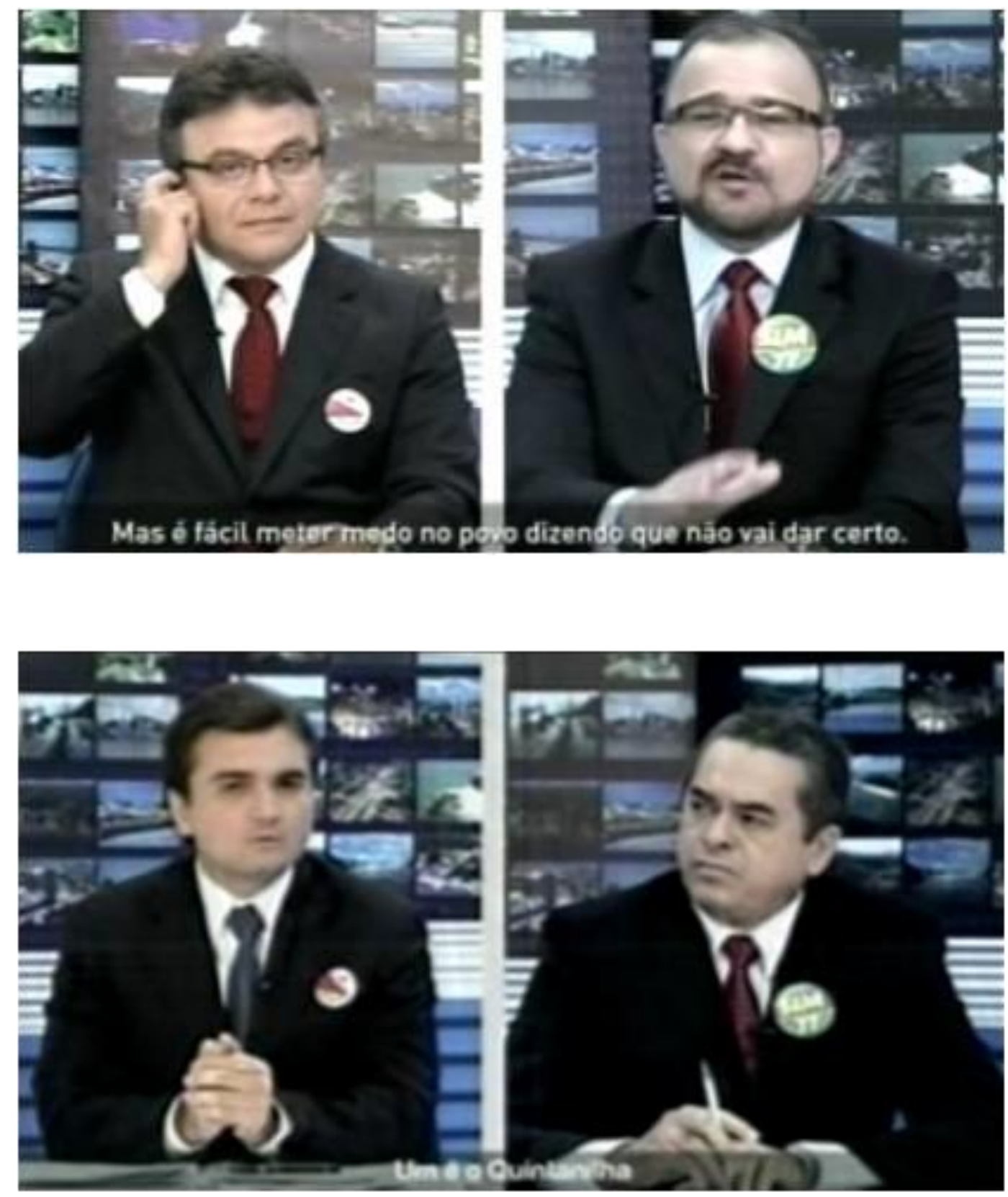

Fonte: Programas da Frente pró Tapajós e contra Tapajós, dia 02 dez. 2011, 19h30-19h40.

Já o deputado federal Zenaldo Coutinho (PSDB-PA), líder da frente contra a criação do Carajás, foi deputado federal durante quatro mandatos e atuou nos bastidores da Câmara Federal para inviabilizar a realização do plebiscito (Bramatti, 2011). Após o quarto mandato como deputado, foi convidado pelo governador do Pará, Simão Jatene, para 
dirigir a Casa Civil, o que lhe garantiu uma aproximação do governo estadual como interlocutor político e, possivelmente, seu direcionamento à liderança de uma das frentes de oposição à divisão (Bramatti, 2011).

À medida que o plebiscito foi se aproximando, em agosto de 2011, Zenaldo Coutinho saiu da Casa Civil para assumir a Secretaria de Proteção e Desenvolvimento Social do Pará (SEEPDS) e, posteriormente, voltou para o cargo de deputado federal. Um afastamento repentino pouco antes do começo da campanha plebiscitária seria uma estratégia para se desvincular da figura do governador, além de preservar sua imagem junto à população das regiões separatistas pelo fato de seu posicionamento ser de oposição à criação dos estados (Aquino, 2013, p. 27).

Após o confronto nas campanhas do plebiscito de 2011, com sua imagem viva na cabeça da população, Zenaldo Coutinho foi candidato à Prefeitura de Belém, em 2012, e venceu. A principal bandeira levantada pelo político, além do apoio ao governador Simão Jatene (PSDB-PA), foi a luta contra a divisão do Pará.

Celso Sabino (PR-PA), líder da frente contra o Estado do Tapajós foi eleito deputado estadual em 2012 e Lira Maia (DEM-PA), líder da frente a favor do Estado do Tapajós, tornou-se deputado federal.

O governador Simão Jatene - 2003/2006, 2011/atual - foi outro personagem envolvido nas campanhas plebiscitárias de 2011 que ganhou visibilidade e críticas quanto a possíveis interesses políticos não desvelados explicitamente, mas que permeavam os argumentos e as estratégias presentes nas campanhas. Isso porque, a priori, Jatene prometeu uma atitude de distanciamento em relação ao plebiscito, pois se viu dividido entre parte de correligionários que era favorável à divisão e outra, contrária ao desmembramento. No entanto, não demorou a se posicionar contra a fragmentação do Pará, o que irritou parte da base de seu governo que defendia a divisão.

Nos programas das frentes favoráveis aos estados, Jatene foi responsabilizado pela situação condenável do Estado, por centralizar os recursos em Belém, marginalizando as 
demais regiões do Pará, problemas que, independentemente de sua participação, ${ }^{12}$ são históricos e também têm outros responsáveis.

O programa vespertino do dia 03/12/2011, da Frente pró Carajás (repetido do dia 30/11, durante o programa da noite), foi um dos programas mais agressivos à imagem do governador Jatene. A apresentadora, relativamente exaltada, em estúdio, criticava o argumento do Não de manutenção da unidade do paraense: "Que união é essa? A do governo com o povo? Aquela que só acontece às vésperas da eleição?". Seguem-se entrevistas com pessoas que, pelo ambiente que as circunda, vestimenta e falas, são pessoas humildes. A legenda na imagem situa o telespectador: são pessoas de Belém. Os entrevistados dialogam com o que foi enunciado pela apresentadora, criticam o governo estadual e cobram atenção da gestão. Volta para a imagem da apresentadora, que sentencia: "Chega! Chegou a hora do Pará saber a verdade! Saber que um dos grandes responsáveis pela pobreza do Pará se chama Simão Jatene!". A responsabilização de Jatene é explicada com a Lei Kandir, cuja aprovação teve o apoio do governador. Sem pagar ICMS, houve um aumento das exportações e do lucro das empresas, mas, nas palavras da apresentadora, "o Pará foi boi de piranha! Sacrificado para que os outros fizessem a festa". As riquezas do Pará teriam ido embora e ao estado restou pobreza sem chances de recuperação.

Após entrar com recurso na Justiça Eleitoral contra as acusações das frentes pró-estados, Jatene conseguiu direito de resposta para defender sua imagem que vinha sendo constantemente desgastada nas campanhas. O direito de resposta do governador foi transmitido no dia 06/12/2011, à tarde, no horário da Frente contra Carajás. O pronunciamento demarcou sua posição contrária à criação dos estados e o projetou como defensor da dignidade do povo. Ele afirmou que as campanhas do Sim estavam colocando "irmãos contra irmãos" e que ele só se manifestou quando "programas na TV, sem compromisso com a verdade, agrediram nossa gente e seus sentimentos" e que ele não permitiria que isso atingisse a autoestima da população paraense, "colocando em risco a unidade de um povo e a convivência fraterna depois da votação". Jatene, além de

${ }^{12}$ Almir Gabriel (1995-2003), Simão Jatene (2003-2007; 2010-atual). 
defender sua imagem, apresentou ações realizadas por seu governo e ratificou sua aliança com as frentes contrárias aos novos estados.

Todos os políticos mencionados reviveram os embates travados durante as campanhas do plebiscito de 2011 como uma das principais estratégias eleitorais para alcançar a vitória nas eleições seguintes.

\section{Considerações finais}

Entendeu-se, portanto, a partir de discussão baseada em Gomes (2004), que os grupos antagônicos que se apresentaram na propaganda do plebiscito pretenderam também aumentar o seu poder de concretizar as decisões que agradam aos seus interesses, com o acúmulo do máximo de poder político possível, fazendo com que o êxito de um, representasse o fracasso do outro e que se incrementasse sua política de imagem - para futuras eleições políticas, por exemplo - garantindo, assim, que o seu projeto de Estado se cumprisse, hegemonicamente.

Os arranjos políticos empregados como estratégias na disputa pelo poder tiveram como objetivo velado garantir o ingresso de novas lideranças políticas e econômicas que, por sua vez, entraram em conflito com grupos que pretendem reproduzir sua hegemonia de controle das estruturas de poder. Esse controle era até então exercido por grupos já sedimentados e sob ameaça de se enfraquecerem com a ascensão de outras lideranças emancipacionistas.

A pretensão de controle do Pará, para ser invisibilizada, não reconheceu as particularidades históricas das regiões do Carajás e do Tapajós que estavam à frente das justificativas de emancipação. As frentes de campanha foram inábeis em construir uma propaganda que produzisse identificação do eleitor com as especificidades de cada região.

Vale ressaltar duas mudanças fundamentais em relação à diminuição do território paraense com a aprovação dos novos estados pela população, interessantes às elites 
políticas em ascensão, mas indesejadas para as elites consolidadas. A primeira diz respeito à perda das receitas com impostos e recursos federais, a segunda concerne à redução do quantitativo de representantes no Congresso Nacional e na Assembleia Legislativa do Estado.

O embate entre os campos da comunicação e da política, por vezes, tornou confusos os modos de informar sobre o plebiscito - os projetos, as implicações dos mesmos e as soluções para os problemas reclamados. Esse fato seria devido ao ineditismo na realização de um pleito para a decisão em relação a ideias e, consequentemente, na inexperiência dos políticos envolvidos com a apresentação dessas propostas? Ou seria mais um artifício da propaganda de pessoas ou grupos, frequentemente utilizada em detrimento da informação política voltada para o interesse público? Essa é uma importante estratégia de propaganda articulada para conduzir, conforme Gomes (2004, p. 209) a uma "confusão entre a imagem do político e a imagem da coisa pública".

Vários momentos do HGPE do plebiscito no Pará são emblemáticos desta espécie de confusão arquitetada, como trechos do debate, por exemplo, que mostraram o caminho oposto à explicação dos projetos de criação dos estados, aproximando-se da competição eleitoral de candidatos. Além disso, outro fator foi a presença constante do governador do Pará, que deveria manter uma posição neutra enquanto chefe de Estado, mas adotou posicionamentos e posturas políticas que o colocaram em papel de destaque nos debates.

Os políticos ganharam evidência, bem como suas alianças, trajetórias e ações políticas, o que pode ter sido proposital e estratégico para dar visibilidade a estes e, por isso, inferirse que a campanha plebiscitária de 2011 serviu como uma fonte de capitalização de argumentos e construção de uma política de imagem que seriam retomados nas disputas eleitorais seguintes, graças ao precioso espaço de exposição na mídia que é o HGPE.

\section{Referências}

ABREU, Alzira; LATTMAN-WELTMAN, Fernando; KORNIS, Mônica. Mídia e política no Brasil: jornalismo e ficção. Rio de Janeiro: FGV, 2003. 
ALMEIDA, Jorge. Marketing político: hegemonia e contra-hegemonia. São Paulo: Fundação Perseu Abramo, 2002.

AQUINO, Evelyn. A encenação político-partidária do plebiscito no Pará: reflexões sobre as estratégias comunicativas no debate eleitoral. 2013. 54 f. Monografia (Especialização em Jornalismo, Cidadania e Políticas Públicas) - UNAMA, Belém, 2013.

BRAMATTI, Daniel. Em plebiscito, eleitor do Pará rejeita criação de estados, mas expõe divisão. Belém, 12 dez. 2011. Disponível em: <http://www.estadao.com.br/noticias/impresso,emplebiscito-eleitor-do-para-rejeita-criacao-de-estados-mas-expoe-divisao--,809726,0.htm>. Acesso em 13 abr. 2013.

BRASIL. Lei 4.737, de 15 de julho de 1965. Institui o código eleitoral. Disponível em: < http://www.planalto.gov.br/ccivil_03/leis/14737.htm>. Acesso em: 18 jan. 2014.

BRASIL. Resolução 23.354, de 18 de agosto de 2011. Dispõe sobre a propaganda plebiscitária e as condutas ilícitas nos plebiscitos no Estado do Pará. Disponível em: <http://www.justicaeleitoral.jus.br/arquivos/resolucao-23354>. Acesso em: 15 jul. 2013.

DIAS, Marcia. Campanha dialógica, pseudo-dialógica ou um "diálogo de surdos": uma proposta teórico-metodológica de análise das candidaturas presidenciais no Horário Gratuito de Propaganda Eleitoral. Anais do IX Encontro da ABCP, Brasília, 2014.

DONOS DA MÍDIA. Disponível em: <www.donosdamidia.com.br>. Acesso em: 26 nov. 2013.

FAUSTO NETO, Antonio; BRAGA, Luiz; PORTO, Sérgio (Org.). Comunicação, cultura e política. Rio de Janeiro: Diadorim, 1994.

FIGUEIREDO, Marcus; ALDÉ, Alessandra; DIAS, Heloísa; VLADIMYR, Jorge. Estratégias de persuasão eleitoral: uma proposta metodológica para o estudo da propaganda eleitoral. Opinião Pública, Campinas, 1997, vol. IV, n. 3, p. 182-203.

GOMES, Wilson. Transformações da política na era da comunicação de massa. São Paulo: Paulus, 2004.

LIMA, Regina. A política e seu funcionamento discursivo: estratégias marcas e contratos. 1995. 154 f. Dissertação (Mestrado em Comunicação e Cultura) - Universidade Federal do Rio de Janeiro, Rio de Janeiro, 1995.

PANKE, Luciana; CERVI, Emerson. Análise da comunicação eleitoral: uma proposta metodológica para os estudos do HGPE. Revista Contemporânea - Comunicação e Cultura, Salvador, 2011, v. 9, n. 3, p. 390-404.

PINTO, Lúcio Flávio. Jornal Pessoal: Pará, plebiscito e interesses, os de ontem e os de sempre. Belém, ano XXVI, n. 533, mar. 2013, p. 10-11. 2011, p. 5 Jornal Pessoal: Redivisão do Pará: 2 e não 3 estados? Belém, ano XXIV, n. 492, jul.

PIOVEZANI, Carlos. Verbo, corpo e voz: dispositivos de fala pública e produção da verdade no discurso político. São Paulo: UNESP, 2009.

RUBIM, Antonio. Comunicação e política. São Paulo: Hacker Editores, 2000. 
SENADO FEDERAL. Plebiscito e referendo. Disponível em: <http://www.senado.gov.br/>. Acesso em: 21 jul. 2013.

TRIBUNAL SUPERIOR ELEITORAL. Disponível em: <http://www.tse.jus.br/eleicoes/plebiscitose-referendos>. Acesso em: 23 mar. 2013.

VEIGA, Luciana; SANTOS, Sandra. O referendo das armas no Brasil: estratégias de campanha e comportamento do eleitor. Revista Brasileira de Ciências Sociais, v. 23, 2008, p. 59-77.

VOX POPULI. Disponível em: <http://www.voxpopuli.com.br/>. Acesso em: 21 jan. 2015.

\section{A autora}

Evelyn Aquino é Publicitária formada na UNAMA e especialista em Jornalismo, Cidadania e Políticas Públicas pela mesma instituição. Mestra em Ciências da Comunicação pela UFPA. Integrante do Projeto de Pesquisa Narrativas Contemporâneas na Amazônia Paraense. evelynaquino18@gmail.com 